\title{
Transport Reversal Due to Typhoon Krosa in the Taiwan Strait
}

\author{
Yu-Hsien Lin ${ }^{1}$, Ming-Chung Fang ${ }^{2}$ and Hwung-Hweng Hwung ${ }^{3 *}$ \\ ${ }^{1}$ Fishing Boat and Marine Engineeirng Research Center, National Cheng-Kung University, Tainan City 70101, Taiwan \\ ${ }^{2}$ Department of Systems and Naval Mechatronic Engineering, National Cheng-Kung University, Tainan City 70101, \\ Taiwan \\ ${ }^{3}$ Tainan Hydraulics Laboratory, \& Senior Executive Vice President, National Cheng-Kung University, Tainan City \\ 70101, Taiwan
}

\begin{abstract}
A comprehensive hydrodynamic model, COMCOT-S, has been aimed at transport reversal in the Taiwan Strait during the period of Typhoon KROSA in 2007. The numerical model is originally based on COMCOT, and a parametric wind model with atmospheric sub-model is imbedded in COMCOT-S for simulating the typhoon-induced currents. The transport characteristics through the Taiwan Strait under the influence of Typhoon KROSA were analyzed using both field observations and numerical simulations during the period from 05 October to 08 October 2007 (GMT+8). The results show that typhoon-induced currents did not fully response to the cease of the northward winds after the flow reversal, representing the influence of other dynamical forces on the flow orientation in the Taiwan Strait. Typhoon-induced wind shear stress and the water level gradient are found to be the direct driving forces of the southward transport events, whereas the atmospheric pressure gradient is dominant after the southward transport peak. By comparing with six numerical experiments, the result of finer grid resolution is in good agreement with the observed current data at THL1 station near Mailiao Harbor. According to the transport simulation of numerical experiments, the Coriolis force is found to play a dominant role in the transport reversal as well, especially in the north Taiwan Strait. Besides, it is more relevant in the Penghu Channel than in the Taiwan Banks that the Coriolis force makes a negative contribution to the southward transport events. Finally, it's verified that the generation of an anticyclonic eddy near the Changyun Rise would not be reached without the contribution of the Coriolis force to the northward transport in the Penghu Channel.
\end{abstract}

Keywords: Typhoon-induced current, typhoon, volume transport, taiwan strait, storm surge, COMCOT-S.

\section{INTRODUCTION}

Taiwan, which is located on the west side of the Pacific Ocean, is usually invaded by typhoons during summer and autumn seasons. A long, shallow channel, which connects the East China Sea (ECS) and South China Sea (SCS) on the continental Shelf of the West Pacific Ocean, is Taiwan Strait. It is about $350 \mathrm{~km}$ long, $180 \mathrm{~km}$ wide with the averaged water depth of $60 \mathrm{~m}$ except over the deep Penghu Channel next to the middle-west side of Taiwan Island [1]. The historical records from Central Weather Bureau (CWB) of Taiwan indicate that there were totally 393 typhoons striking Taiwan from 1897 to 2007. The recurrence probability of typhoon events invading Taiwan is about 3.96 per year. In 2007, there were totally up to five typhoons striking Taiwan during the period from August to October.

Although a lot of investigations of seasonal volume transport through the Taiwan Strait from the ECS to the SCS have been conducted by various authors [2-6], the discussion of the influence of typhoons on transport through the Taiwan

*Address correspondence to this author at the Director, Tainan Hydraulics Laboratory, \& Senior Executive Vice President, National Cheng-Kung University, Tainan City 70101, Taiwan;Tel: 886-6-2741475; Fax: 886-62366265; E-mail: hhhwung@mail.ncku.edu.tw; Working E-mail: vyhlin@mail.ncku.edu.tw
Strait is scanty. Zhang et al. [7] implied that the strong southward transport would occur temporarily during the passage of typhoons over the Taiwan Strait. They also concluded that the typhoon-generated wind stress and the alongstrait water level gradient were the main driving forces in these temporal southward events. Moreover, the contribution of the momentum gradient term to the transport events is less compared with that of the nonlinear advection term. However, the characteristics of transport reversal as typhoons enter the Taiwan Strait have been neglected in these literatures.

To shed more light on the transport reversal [8] induced by typhoons in the Taiwan Strait, a case study of typhoon KROSA in 2007 including the field observations near Mailiao Harbor and model results with systematic numerical experiments were considered in this research. In this paper, the numerical model, COMCOT-S (COrnell Multi-grid Coupled Tsunami model for Storm-surge) adopts explicit staggered leap-frog finite difference scheme in a multi-grid system to solve the nonlinear shallow water wave equation in a spherical coordinate. Since this study was focused on the typhoon-induced transport through the Taiwan Strait, which is the depth-integrated result of volume fluxes, the depthaveraged shallow water equations were used in the numerical simulations. Although the seasonal variation of monsoon winds (e.g. winter wind bursts) plays an important part in 
determining the orientation of ocean currents in the Taiwan Strait, only the contribution of transient extreme weather of typhoon events to strait transport would be taken into account.

\section{MODEL DESCRIPTION}

The hydrodynamic model implemented in this study adopts a spherical coordinate in the multi-grid system. In COMCOT-S, the Non-Linear Shallow water Wave equation (NLSW, hereinafter) can be assigned to each specific sublevel grid and be solved by the staggered leap-frog finite difference scheme. The sub-level grid regions are dynamically connected. In the largest grid (main layer), the earth rotation is relatively prominent and the local water depth in the open ocean is much larger than the propagating wave amplitude. Thus, the nonlinear advective terms and the bottom friction terms can be neglected in this situation. However, as the wave propagates over a continental shelf and approaches coastal regions, the shoaling effect would be increasingly significant. In that case, the nonlinear advective term and bottom frictional term become prominent during the simulation procedure, while the significance of the Coriolis force diminishes. The governing equations, dynamic forcing of the model and the numerical scheme will be described in this section.

\subsection{Governing Equations}

The governing equations, including the depth-averaged continuity equation and the momentum equations, are utilized in a spherical coordinate system as follows.

$$
\begin{aligned}
& \frac{\partial \varsigma}{\partial t}+\frac{1}{R \cos \varphi}\left\{\frac{\partial P}{\partial \psi}+\frac{\partial}{\partial \varphi}(\cos \varphi \cdot Q)\right\}=0, \\
& \frac{\partial P}{\partial t}+\frac{1}{R \cos \varphi} \frac{\partial}{\partial \psi}\left(\frac{P^{2}}{H}\right)+\frac{1}{R} \frac{\partial}{\partial \varphi}\left(\frac{P Q}{H}\right)+\frac{g H}{R \cos \varphi} \frac{\partial \varsigma}{\partial \psi}-f Q \\
& =-\frac{h}{\rho R \cos \varphi} \frac{\partial P}{\partial \psi}+\frac{1}{\rho}\left(F_{\psi}^{s}-F_{\psi}^{b}\right), \\
& \frac{\partial Q}{\partial t}+\frac{1}{R \cos \varphi} \frac{\partial}{\partial \psi}\left(\frac{P Q}{H}\right)+\frac{1}{R} \frac{\partial}{\partial \varphi}\left(\frac{Q^{2}}{H}\right)+\frac{g H}{R} \frac{\partial \varsigma}{\partial \varphi}+f P \\
& =-\frac{h}{\rho R} \frac{\partial P_{a}}{\partial \varphi}+\frac{1}{\rho}\left(F_{\varphi}^{s}-F_{\varphi}^{b}\right),
\end{aligned}
$$

where

$(\psi, \varphi)$ : longitude and latitude of the earth,

$\mathrm{R}$ : earth radius,

$H$ : total water depth $(=a+h)$,

$a$ : free surface elevation,

$h:$ still water depth,

$P, Q$ : volume fluxes in longitude and latitude,

$g$ : gravitational acceleration,
$P_{a}:$ ambient pressure,

$f$ represents Coriolis parameter, equaling to $2 \omega \sin \phi$, whereas $\omega$ is the angular speed while the earth rotates.

The bottom shear stress terms are modeled by using the Manning's formula as follows,

$$
\begin{aligned}
& F_{\psi}^{b}=\frac{\rho g n^{2}}{H^{7 / 3}} P\left(P^{2}+Q^{2}\right)^{1 / 2}, \\
& F_{\varphi}^{b}=\frac{\rho g n^{2}}{H^{7 / 3}} Q\left(P^{2}+Q^{2}\right)^{1 / 2},
\end{aligned}
$$

In the present study, the Manning's relative roughness coefficient, $n$, is given as bottom friction coefficient.

The surface wind shear stress is computed by conventional bulk formula as:

$$
F^{s}=\rho_{a} C_{d}|\vec{V}| \overrightarrow{V_{w}}
$$

where $\overrightarrow{V_{w}}$ is wind speed at height of $10 \mathrm{~m}, \rho_{a}$ is air density and the drag coefficient, $C_{d}$, would be introduced in the next section.

\subsection{Modeling of Typhoon Winds}

The $C_{d}$ coefficient in Eq. (6) is assumed to vary with

$$
10^{3} C_{d}=\left\{\begin{array}{lr}
2.16 & \left|\overrightarrow{V_{w}}\right| \geq 26 m s^{-1} \\
0.49+0.065\left|\overrightarrow{V_{w}}\right| & 10 m s^{-1} \leq\left|\overrightarrow{V_{w}}\right|<26 m s^{-1} \\
1.14 & 3 m s^{-1} \leq\left|\overrightarrow{V_{w}}\right|<10 m s^{-1} \\
0.62+1.56 /\left|\overrightarrow{V_{w}}\right| & 1 m s^{-1} \leq\left|\overrightarrow{V_{w}}\right|<3 m s^{-1} \\
2.18 & \left|\overrightarrow{V_{w}}\right|<1 m s^{-1},
\end{array}\right.
$$

The $C_{d}$ formula follows the result by Large and Pond [9] when the local wind speed is less than $26 \mathrm{~ms}^{-1}$, otherwise, it would be assumed as a constant value suggested by Powell et al. [10].

The Holland model [11] provides a wind field directly from input values of $R_{\max }$ (radius of the maximum winds) and $P_{c}$ (the atmospheric pressure in the storm center), based on the exponential distribution of the atmospheric pressure with a peakness parameter $B$.

$$
P=P_{c}+\left(P_{n}-P_{c}\right) \exp \left[-\left(\frac{R_{\max }}{r}\right)^{B}\right]
$$


where $P$ is the atmospheric pressure at radius $r$ (radius starting from the storm center) and $P_{n}$ is the ambient pressure. The resulting wind speed suggested by Phadke et al. [12] is called the gradient wind speed and is given by

$$
V_{g}=\sqrt{\frac{B\left(P_{n}-P_{c}\right)}{\rho_{a}}\left(\frac{R_{\max }}{R}\right)^{B} \exp \left[-\left(\frac{R_{\max }}{r}\right)^{B}\right]+\frac{r^{2} f^{2}}{4}}-\frac{r f}{2},
$$

where $f$ is the Coriolis parameter and $\rho_{a}$ is the air density. The wind speed near $R_{\max }$ becomes

$$
V_{g \max }=\sqrt{\frac{B\left(P_{n}-P_{c}\right)}{\rho_{a}} \exp \left[(-1)^{B}\right]+\frac{r^{2} f^{2}}{4}}-\frac{r f}{2},
$$

Harper and Holland [13] recently suggested an empirical relation for $B$

$$
B=2-\frac{P_{c}-900}{160} \text { for } 1.0<B<2.5 \text {, }
$$

For a stationary typhoon, the inflow angle at the surface is approximated as a function of $R$ as:

$$
\begin{aligned}
& \beta=10^{\circ}\left(1+\frac{R}{R_{\text {max }}}\right)^{\text {for }} 0 \leq R<R_{\text {max }}, \\
& \beta=20^{\circ}+25^{\circ}\left(\frac{R}{R_{\text {max }}}-1\right) \text { for } R_{\text {max }} \leq R<1.2 R_{\text {max }}, \\
& \beta=25^{\circ} \text { for } R \geq 1.2 R_{\text {max }},
\end{aligned}
$$

where $\beta$ is measured inward from the isobars [14].

Since typhoon winds in the northern hemisphere spin in the counter-clockwise direction, the forward motion of typhoon would increase the wind speed in the right quadrants and decrease the wind speed in the left. Jelesnianski [15] suggested a following equation to account for the forward motion of a slow-moving typhoon:

$$
U(R)=\frac{R_{\max } R}{R_{\max }^{2}+R^{2}} V_{f},
$$

where $V_{f}$ is the forward velocity of the storm and $U(R)$ is the correction term, which is vectorially added to the axisymmetric wind field from the parametric model.

\subsection{Numerical Scheme}

Explicit leap-frog finite difference scheme has been adopted to solve the NLSW in the previous literatures [16, 17]. The nonlinear advective terms are discretized with an upwind scheme. In general, the upwind scheme is considerably stable and produces some numerical dissipation. But if the velocity gradient in the fluid field is not too steep and if the stability criterion, $\sqrt{g h} \cdot \Delta t / \Delta x<1$, is satisfied, upwind formulation is preferred for nonlinear advective terms [18]. The linear terms of the governing equations are discretized by the leap-frog finite difference scheme, as well.

By using multi-grid system, COMCOT-S is capable of simultaneously calculating the wave propagation in deep ocean and the inundation in the coastal areas of interest. In the multi-grid system, the finer grids adopt a smaller grid size and time step and are nested inside a larger grid. During the simulation procedure, the finer grids will be assigned to resolve wave profiles in shallow water regions. Therefore, when the water depth varies within the largest layer, it might be desirable that different grid size and time step size be employed in different sub-grids. At the beginning of each time step, along the boundary of two different grids, the volume flux is interpolated from the larger grid into the finer grid. The water surface elevations and the volume fluxes in the finer grids are calculated and the resulting free-surface elevations are averaged to update those values in the coarser grids. In addition, the volume fluxes in the coarser grids can be updated. The advantage of multi-grid system is that we can simulate the dynamics of storm-induced currents in the nearshore regions with high spatial and temporal resolutions, and can maintain a high computational efficiency, simultaneously.

A dynamically coupled system of nested grids was employed to simulate the storm surge propagation from the Pacific Ocean toward the Taiwan Strait with the flow variation under consideration. Table 1 gives the spatial extent and the resolution of the coarser and finer grids as well as the governing equations used. The outer domain (Fig. 1), covered with the largest grid size (main grid, L1 hereinafter), ranges from $115^{\circ} \mathrm{E}$ to $135^{\circ} \mathrm{E}$ in longitude and from $15^{\circ} \mathrm{N}$ to $29^{\circ} \mathrm{N}$ in latitude, with a grid resolution of $1^{\prime}(\sim 1.8 \mathrm{~km})$. The bathymetry and land elevation for L1 were extrapolated and obtained from ETOPO1 data (http://www.ngdc.noaa.gov/ $\mathrm{mgg} / \mathrm{global} / \mathrm{global} . \mathrm{html}$ ) and 2007 geodetic survey data of industrial park of an offshore-island in Yunlin County, with grid dimension $1201 \times 841$.

The bathymetric data for L2, as indicated in Fig. (2), ranges from $116.5^{\circ} \mathrm{E}$ to $121.0^{\circ} \mathrm{E}$ in longitude and from 23.0

Table 1. Model Information of the Nested Grids Implemented in the Numerical Simulations

\begin{tabular}{|c|c|c|c|c|}
\hline \multirow{2}{*}{ Grid No. } & \multicolumn{2}{|c|}{ Extent of Grid (Geographic, WGS94) } & \multirow{2}{*}{ Grid Dimension } & \multirow{2}{*}{ Grid Resolution } \\
\cline { 2 - 5 } & Longitude $\left({ }^{\circ} \mathbf{E}\right)$ & Latitude $\left({ }^{\circ} \mathbf{N}\right)$ & $1204-841$ & $1 \mathrm{~min}(\sim 1.8 \mathrm{~km})$ \\
\hline \hline 1 & $115-135$ & $15-29$ & $1351-601$ & $0.2 \mathrm{~min}(\sim 360 \mathrm{~m})$ \\
\hline 2 & $116.5-121$ & $23-25$ & & \multirow{2}{*}{. } \\
\hline \hline
\end{tabular}




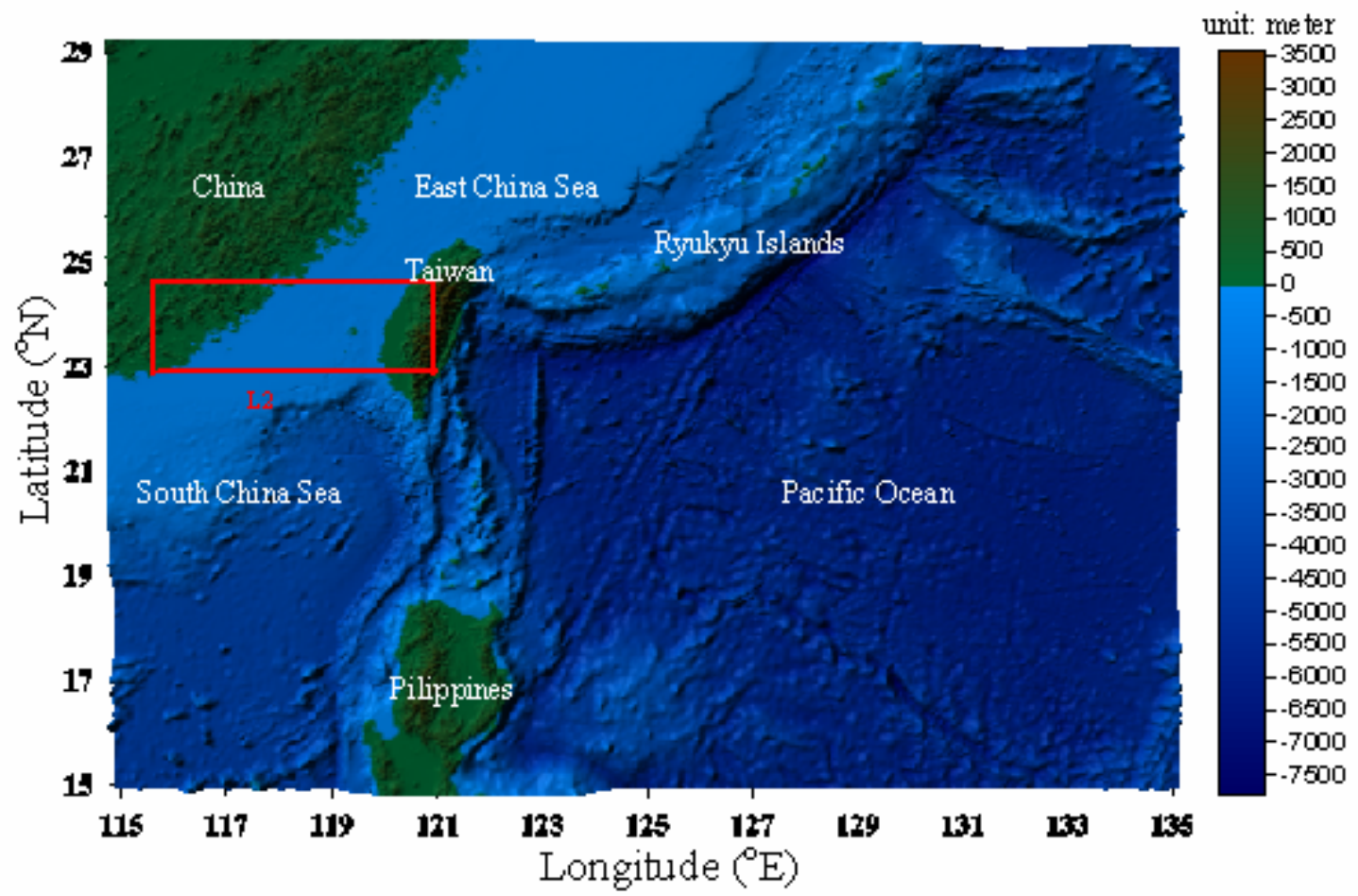

Fig. (1). Model domains for the ocean (L1) and coastal (L2) grids with topographic and bathymetric contours in meters.

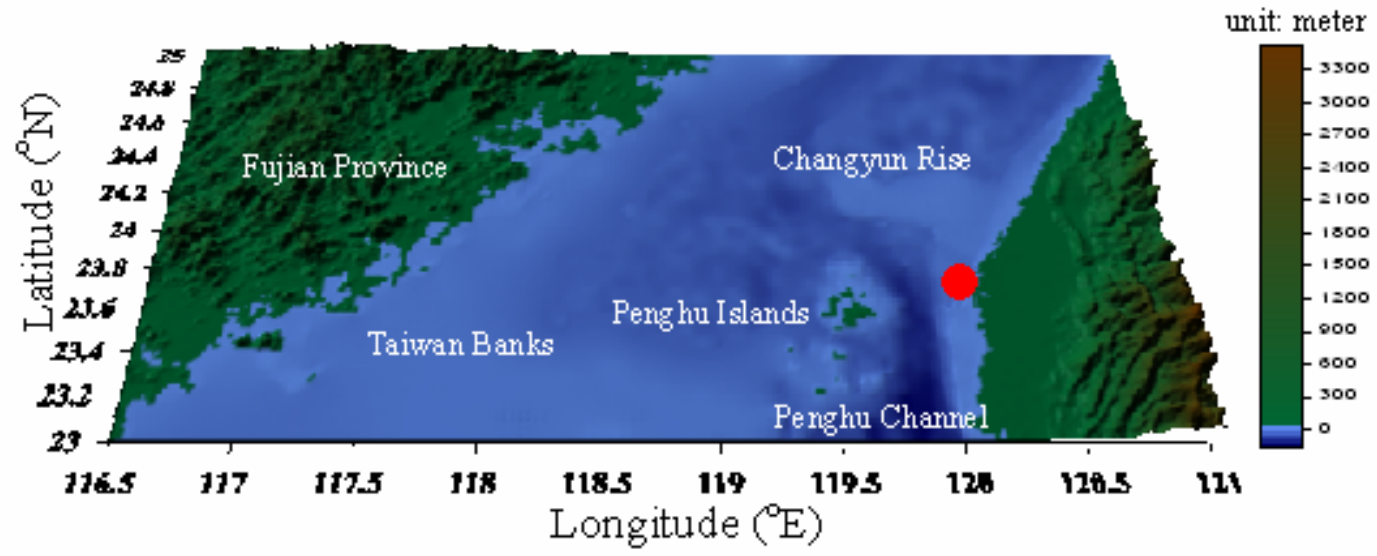

Fig. (2). The perspective view of L2 grid with topographic and bathymetric contours in meters.

${ }^{\circ} \mathrm{N}$ to $25.0^{\circ} \mathrm{N}$ in latitude, with a grid resolution of $0.2^{\prime}(\sim 360$ $\mathrm{m})$. The bathymetry data of L2 were interpolated from ETOPO1 and extrapolated from 2007 bathymetry survey data of industrial park of an offshore-island in Yunliin County as well, with a grid dimension of $1351 \times 601$. According to the suggestion by Flather [19], the depth-averaged velocity on open boundaries is

$$
\bar{u}_{n}=\bar{u}_{n}+\sqrt{\frac{g}{H}}\left(\zeta-\zeta^{0}\right)
$$

where $\bar{u}_{n}$ is the depth-averaged, velocity normal to open boundaries of COMCOT-S and $u_{n}$ is the current input on the open boundaries at time $t$. The modeling surge elevation $\xi^{0}$ is located on the open boundaries of COMCOT-S. Further- more, the zero normal gradient condition for sea grids is used on all open boundaries.

\section{FIELD MEASUREMENTS}

The Penghu Channel (PHC, hereinafter) is adjoining to the west side of Yunlin coasts, with the Changyun Rise (CYR) blocking on the north side (Fig. 2). Measurements of sustained winds were sparse in this area as well as the current measurements. During the period of Typhoon KROSA passage (05 08 October, 2007, GMT+8), a series of welldocumented records of real-time wind and current data were measured by the observational platform (THL1, hereinafter) of Tainan Hydraulics Laboratory, which was situated on the southwest side of Mailiao Harbor, Yunlin County. The information of sustained winds were recorded by a wind moni- 
Table 2. Young 05103 Wind Monitor

\begin{tabular}{|l|l|}
\hline Measurement & $\begin{array}{l}\text { 1. Wind Speed } \\
\text { 2. Wind Direction }\end{array}$ \\
\hline Ranges & $\begin{array}{l}1.0 \sim 60 \mathrm{~m} / \mathrm{s} \\
2 . \quad 360^{\circ} \text { mechanical, } 355^{\circ} \text { electrical }\left(5^{\circ} \text { open }\right)\end{array}$ \\
\hline Output Frequency & $0.098 \mathrm{~m} / \mathrm{s} \mathrm{per} \mathrm{Hz}$ \\
\hline Transducer Output & Regulated DC voltage, $15 \mathrm{VDC} \max$ \\
\hline Gust survival & $100 \mathrm{~m} / \mathrm{s}$ \\
\hline Accuracy & $1 . \quad \pm 0.3 \mathrm{~m} / \mathrm{s}$ \\
& $2 . \quad \pm 3^{\circ}$ \\
\hline
\end{tabular}

Table 3. Current Self-recording Type Instrument (Valeport 308)

\begin{tabular}{|c|c|c|c|c|}
\hline Sensor Specifications & Type & Range & Accuracy & Resolution \\
\hline \hline Speed & Impeller & $0.03 \sim 5 \mathrm{~m} / \mathrm{s}$ & $0.15 \sim 5 \mathrm{~m} / \mathrm{s}<1.5 \%$ of reading & $0.01 \mathrm{~m} / \mathrm{s}$ \\
\hline Direction & Flux gate compass & $0^{\circ} \sim 360^{\circ}$ & $\pm 2^{\circ}$ & $0.25^{\circ}$ \\
\hline
\end{tabular}

tor, Young 05103 (Table 2), which was mounted $12 \mathrm{~m}$ above the sea level over the platform. The interval of wind measurement is 3 minutes. The current data were obtained from the current self-recording type instrument, Valeport 308 (Table 3), which was deployed $-13 \mathrm{~m}$ beneath the mean sea level. Each data interval of currents is 5 minutes for data acquisition.

After data acquisition is over, each data set would be subsequently stored on the hard disk. The data transmission is based on GPRS (General Packet Radio Service), which was deployed by Tainan Hydraulics Laboratory. Consequently, the digital signals of winds and currents would be transmitted back to the information center at Tainan Hydraulic Laboratory for further processing.

At the local station, the tidal components of ocean currents were analyzed via a least square fit method. Then the tidal components were removed from the original data. The filtered signals via a nonlinear second power function fit method were performed for the wind and current data after removing the observational noises.

\section{RESULTS AND DISCUSSION}

\subsection{Typhoon KROSA}

As typhoon KROSA passed through the west-central Philippine Sea about 500 miles northeast of the Philippines in the general direction of Taiwan, it was increasingly developed into a powerful category 4 typhoon on the SaffirSimpson scale. KROSA is the Cambodian word for crane. Typhoon KROSA experienced rapid intensification beginning at around 02:00 02 October $(\mathrm{GMT}+8)$ due to enhanced upper level outflow and ocean warm eddy. This allowed KROSA to reach super typhoon strength by 14:00 05 October $(\mathrm{GMT}+8)$ and attain maximum intensity of $55 \mathrm{~m} / \mathrm{s} 84 \mathrm{hrs}$ later (Table 4). Typhoon KROSA made landfall on Ilan County at around 22:30 October $06(\mathrm{GMT}+8)$ and (Fig. 3), subsequently, tracking along the northeastern coast of Taiwan and departured at around 23:20 October 06 (GMT+8). The last bulletin on KROSA was issued by the Joint Typhoon Warning Center at 02:00 09 October (GMT+8), while it dissipated as an extra-tropical system in the ECS.

Typhoon KROSA was one of the most intense typhoons to strike Taiwan in 2007. Nine fatalities were reported and a further 57 injuries occurred as Typhoon KORSA tracked over Taiwan Island. Taiwan Island sustained property damage, flight cancellations and extensive loss of electricity during the period of Typhoon KROSA. The mountain areas received severe significant precipitation and there were six townships where landslides were reported. As Typhoon KROSA made landfall with an intensity of approximately $40.54 \mathrm{~m} / \mathrm{s}$, it caused about 37 million dollars in agricultural losses.

\subsection{Driving Forces and Typhoon-Induced Currents}

In this study, COMCOT-S was used to calculate the atmospheric pressure and sea surface wind stress for the subsequent simulation of volume fluxes and surge heights. The model includes the multi-grid system with two different grid resolutions and a function of moving boundary scheme. COMCOT-S requires four input parameters, such as the location and pressure of storm center, the radius of the maximum winds, and the ambient pressure. All the necessary parameters mentioned above were acquired from CWB. The atmospheric pressure and wind fields were calculated at 3hourly interval by COMCOT-S. Subsequently, the numerical model was driven for 60 hours with 1 second time-step size using the atmospheric pressure and wind data as driven inputs.

Fig. (4a, b) show comparisons between observations performed at the THL1 station near Mailiao Harbor and the modeling wind data in the longitudinal and latitudinal directions, respectively. The correlation coefficient $\left(\mathrm{C}_{\mathrm{r}}\right)$ value 
Table 4. The Information of Typhoon KROSA (Source from CWB)

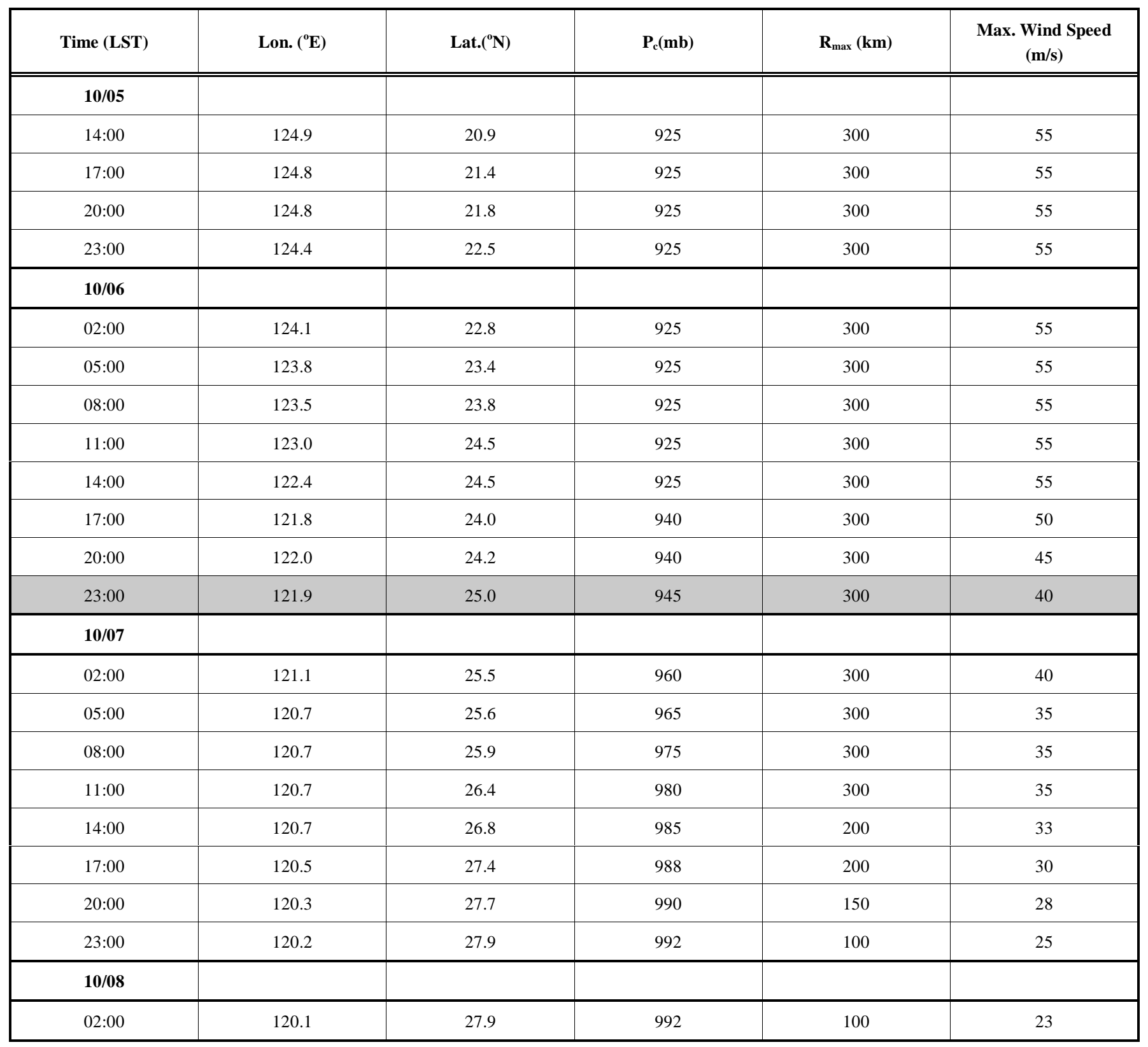

between their wind speeds in the longitudinal direction exceeds 0.84 while the root-mean-sqaure error is $5.56 \mathrm{~m} / \mathrm{s}$. For the wind components in the latitudinal direction, the $C_{r}$ is 0.93 and the RMS error is $4.55 \mathrm{~m} / \mathrm{s}$. In general, the simulated wind data compare well with the field observations in this sea area, and the wind components in the latitudinal direction shows better comparisons than those in the longitudinal direction. In Fig. (4c, d), the time series of storm-induced currents of both observed and numerical results are illustrated in the longitudinal and latitudinal directions as well. The results show that the current series in these two directions varied almost synchronously and the curves of numerical and observed data were nearly coincident. Although the current data in the latitudinal direction (Fig. 4d) indicate that an underestimated value of numerical results appeared in the southward current peak, the current data basically show good agreements during this period. Both the $\mathrm{C}_{\mathrm{r}}$ values between current speeds of simulations and observations are found to exceed 0.95 in the longitudinal and latitudinal direction, respectively. For the RMS errors in Fig. (4c, d), the results appear the values of $0.019 \mathrm{~m} / \mathrm{s}$ and $0.041 \mathrm{~m} / \mathrm{s}$, respectively.

Fig. (5a-c) indicate the distribution of current vector fields in the Taiwan Strait with respect to the time-series of typhoon induced currents and local winds at THL1 computed from COMCOT-S at 19:00 06 October (GMT+8). The typhoon center was then located off the east coast of Taiwan Island, four hours before landing on Ilan County. The results in Fig. (4) show that the typhoon-induced currents at THL1 are highly sensitive to the typhoon winds due to the relatively shallower water depth of the observation station (about $-13 \mathrm{~m}$ ) near the coasts. It's evident in Fig. (5a) that typhoon induced currents mainly moved southwestward along the 


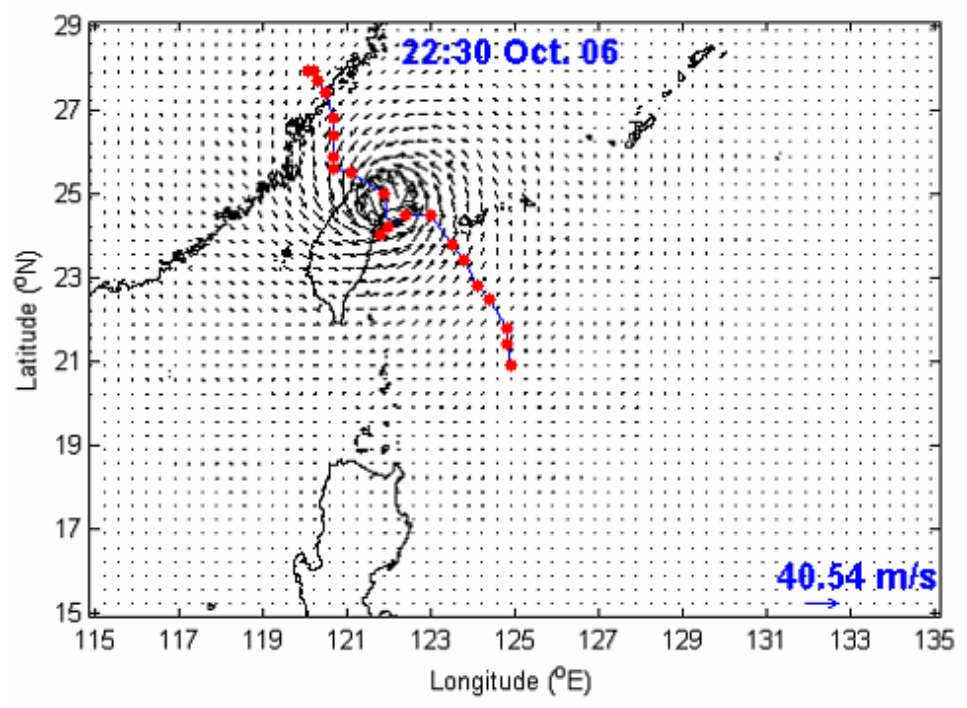

Fig. (3). The best track of Typhoon KROSA during the period of October 05 to 08 (GMT+8). The wind vector field calculated by COMCOT-S indicated the distribution when typhoon KROSA made landfall on Ilan County. Note that the time interval along the typhoon track is 3 hrs.
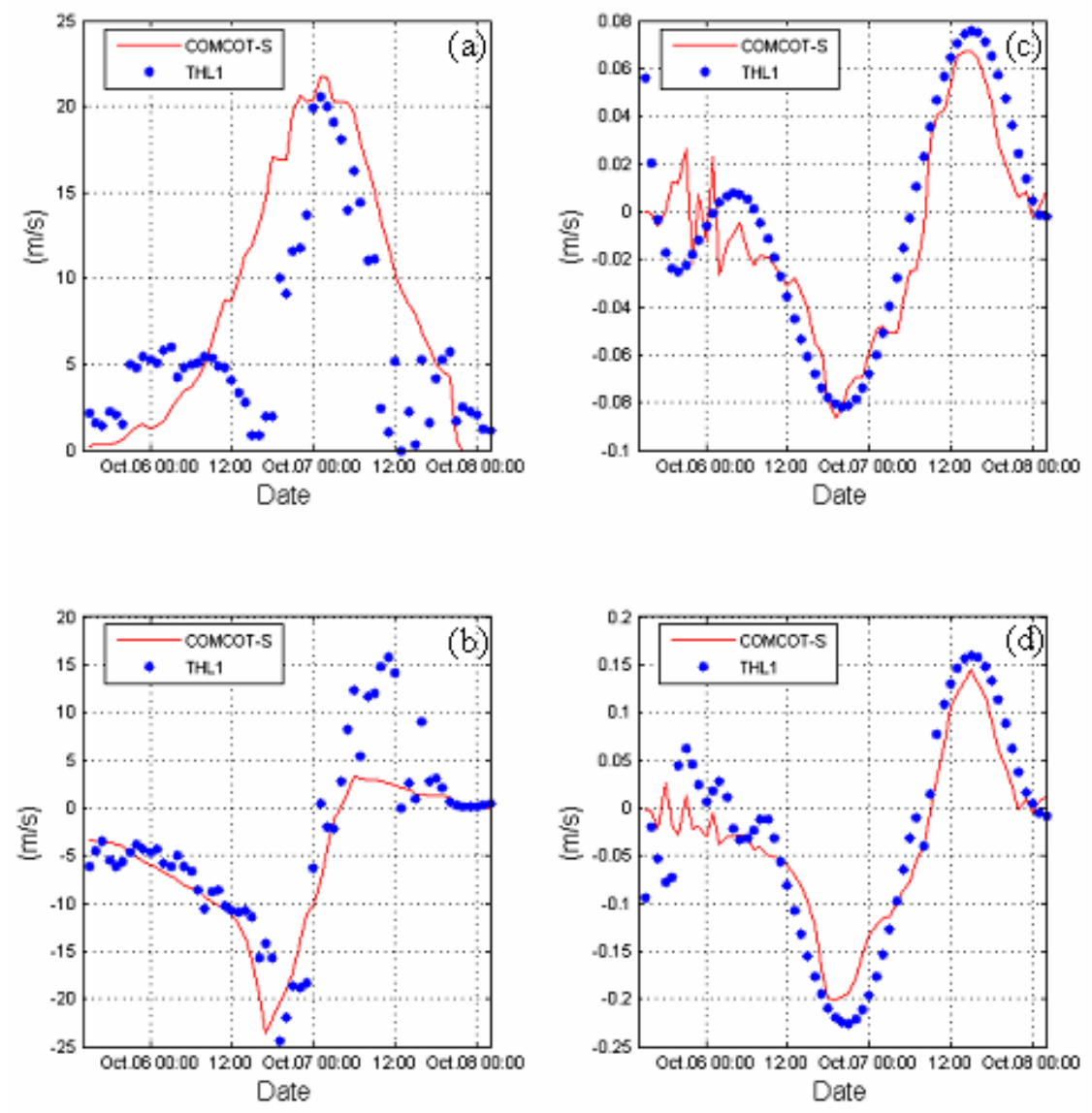

Fig. (4). Comparisons of THL1 observation and model simulation for the wind data (a) in the longitudinal direction, (b) in the latitudinal direction; and for the current data (c) in the longitudinal direction, (d) in the latitudinal direction during the period of Typhoon KROSA along the track shown in Fig. (3).

west Taiwan coasts, passed through the CYR and then entered the PHC, the major pathway by which the southward flow enters the SCS. The modeling results in Fig. (5b-c) reveal that the southward current peak at THL1 is almost in accordance with the maximum southward typhoon wind peak, with a time-lag of two hours.

Fig. (6a) shows the corresponding current pattern, in which the location of typhoon center was presently at (120.7 

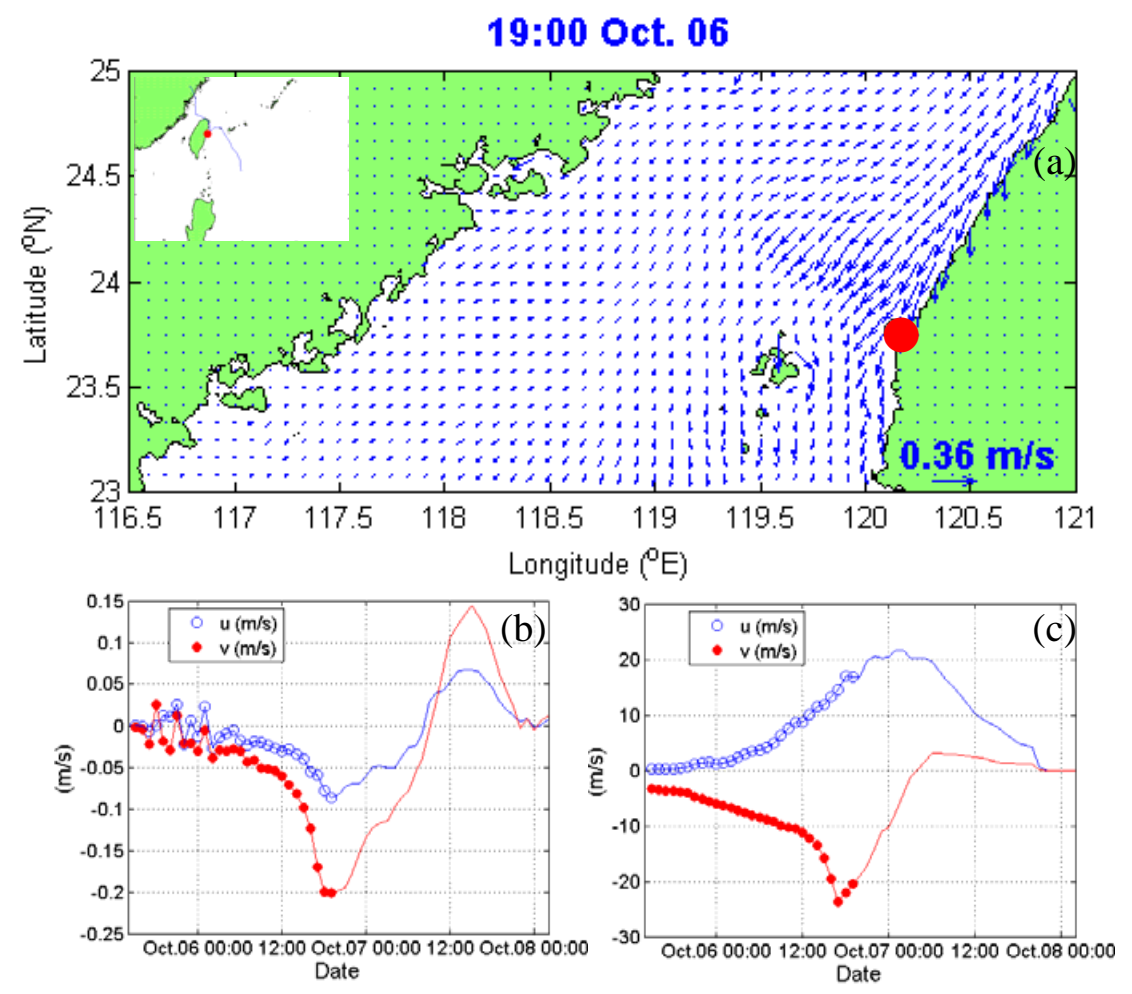

Fig. (5). (a) The variation of typhoon-induced currents in the Taiwan Strait. Time series of modeling (b) typhoon-induced currents and (c) wind speeds at THL1 (indicated as the red solid circle) at 19:00 06 October (GMT+8).

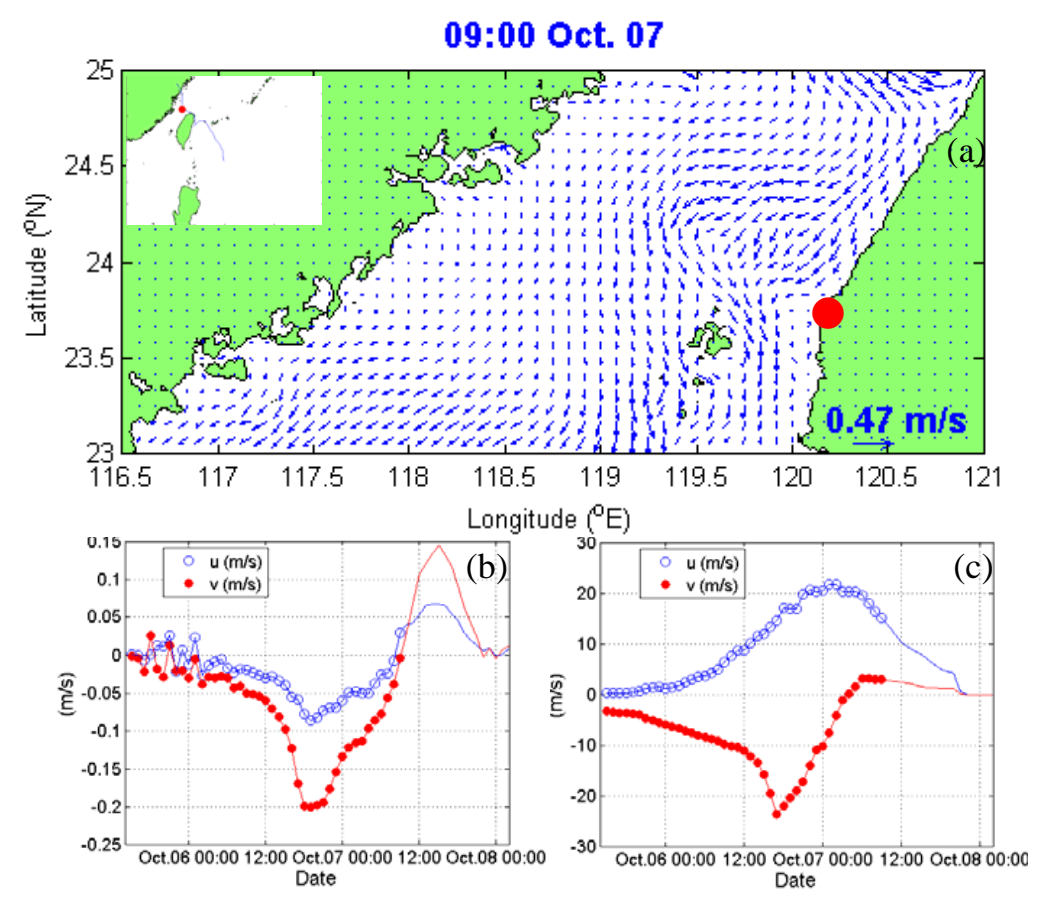

Fig. (6). The same as in Fig. (5). but at 09:00 07 October (GMT+8).

${ }^{\circ} \mathrm{E}, 25.9^{\circ} \mathrm{N}$ ) in the north side of the Taiwan Strait. In the sea area of central Taiwan Strait, the southward currents were relatively unimpeded by the CYR and bifurcated slightly at the north reach of the Taiwan Strait. The southward flow observed at THL1 became nearly stagnant (Fig. 6b) as the original southeastward winds ended and turned eastward (Fig. 6c). Particularly, the southward intrusion flows over and beyond the CYR presented an evident reduction in magnitude. It's clearly found that a U-shaped flow pattern occupying in the north portion of the CYR, with a nearly stagnant flow observed at THL1. It's noted that one branch continues southward over the CYR, while the other branch moves around the CYR along its western flank. 


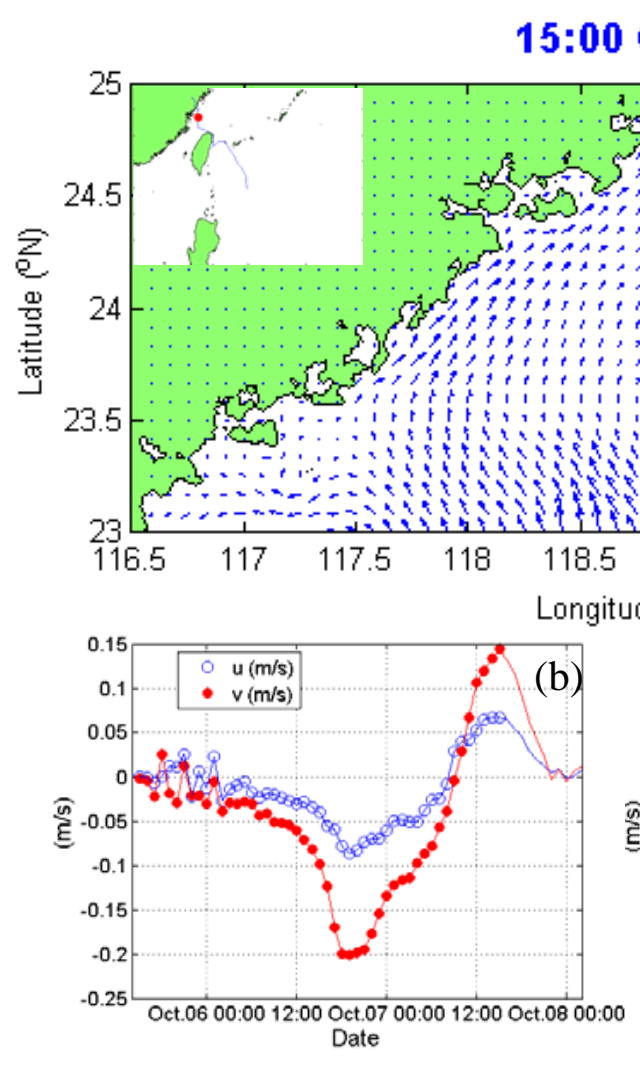

Fig. (7). The same as in Fig. (5). but at 15:00 07 October (GMT+8).

As Typhoon KROSA moved close to the mainland coasts $\left(120.7^{\circ} \mathrm{E}, 26.8^{\circ} \mathrm{N}\right)$, it is interesting to find that the flow pattern in the Taiwan Strait (Fig. 7a) turned northward principally. Compared to the case of typhoon center in the middle reach of the Taiwan Strait (Fig. 6c), the northeastward winds weakened even further as the low-pressure system decreased its strength $\left(P_{a}=985 \mathrm{mb}\right)$. Although the strongest northward current was reached at 15:00 07 October $(\mathrm{GMT}+8)($ Fig. 7b), the northward winds continued to decrease its intensity in the latitudinal direction (Fig. 7c). It's assumed that other external forces of the typhoon may have influences on the flow reversal in the Taiwan Strait. In addition, the formation of an anticyclonic eddy was well developed in the north reach of the Taiwan Strait, which is near to the northwest side of the CYR. Wu et al. [1] suggested that the ocean currents passing through the Taiwan Strait in winter will induce an anticyclone due to the existence of the CYR. Meanwhile, it is seen that the confluence of northward and southward currents will complicate the flow pattern in the middle reach of the Taiwan Strait.

\subsection{Typhoon-Induced Transport Events through the Taiwan Strait}

Typhoon-induced transport through the entire strait was calculated directly by using the output current data from COMCOT-S and integrated bathymetry information in this study. The northern section is averaged over the domain from $119{ }^{\circ} \mathrm{E}$ to $121.25^{\circ} \mathrm{E}$ and from $25^{\circ} \mathrm{N}$ to $25.25{ }^{\circ} \mathrm{N}$. The southern section is averaged over the domain from $116.5^{\circ} \mathrm{E}$ to $120.25{ }^{\circ} \mathrm{E}$ and from $23^{\circ} \mathrm{N}$ to $23.25^{\circ} \mathrm{N}$. As for the volume transport calculation, the velocity data perpendicular to the transection were depicted at each segment and averaged over one hour. The output velocity was assigned to the center of each grid and the local water depth was gridded by the integrated bathymetry data for each segment from west to east boundary. Subsequently, the volume transport $(q)$ through the transection at each time-step could be calculated as:

$q=\sum_{i=1}^{N} v_{t=1 \ldots, T, i} \cdot\left(h_{i} \cdot \Delta b\right)$

where $\Delta b=R \cos \varphi \cdot \Delta \psi$ is the width of each segment, $i$ is the segment number, $N$ is the total number of the segments along the transect, and $h_{i}$ is the local water depth at each segment. Note that $t$ is the time-step number, and $T=60$ hours is the total number of the recorded time history.

Fig. (8) indicates the mean values of transport throughout the Taiwan Strait and over the northern and southern sections, respectively. The transport series through these two sections are almost consistent and vary with a time lag of 5 hours for the southward transport peak. The southward transport peak through the northern entrance was occurred at 03:00 07 October $(\mathrm{GMT}+8)$, whereas the peak of the southern section was at 08:00 07 October (GMT+8) It is interesting to find that the transport reversal through the northern section was occurred at 16:30 07 October $(\mathrm{GMT}+8)$ which was three hours slower than that through the southern section (13:30 07 October, GMT+8). In order to obtain the characteristics of the transport events due to typhoons and analyze the influences of the driving forces on the transport variation through the Taiwan Strait, dynamic analysis is necessary and would be discussed in the following. The modeling results of 


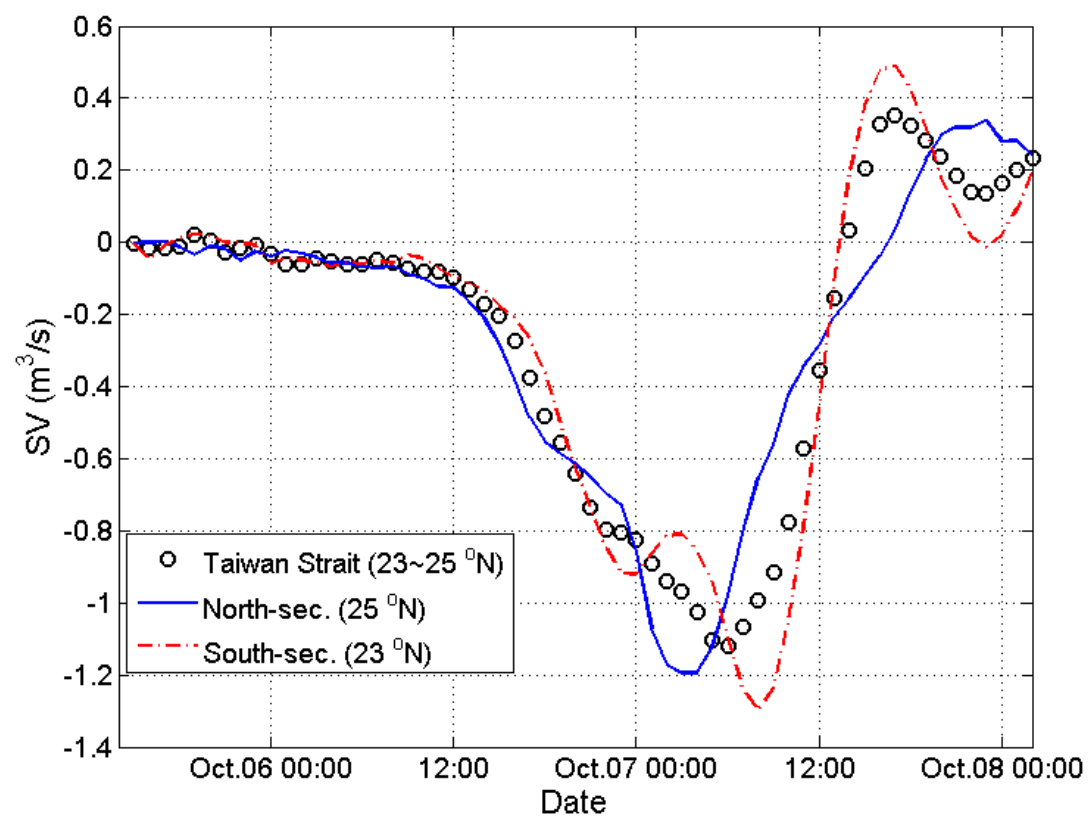

Fig. (8). Time series of volume transport throughout and at the both sections of the Taiwan Strait during the period of 14:00 05 October to 02:00 08 October $(\mathrm{GMT}+8)$. Note that the northward transport is positive and the southward transport is negative.
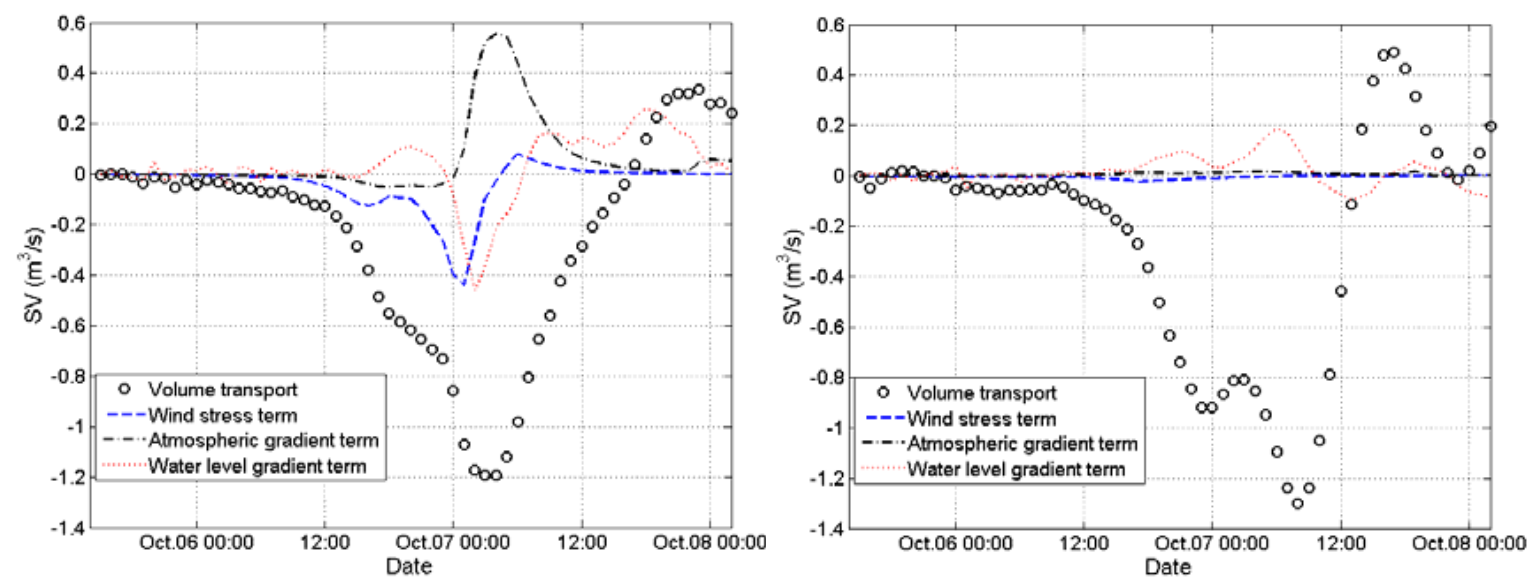

Fig. (9). Time series of volume transport components at the (a) north section and (b) south section of the Taiwan Strait during the period of 14:00 05 October to 02:00 08 October (GMT+8).

Fig. (5-7) present that the flow reversal in the Taiwan Strait was occurred as Typhoon KROSA moved close to the mainland coasts. The transport reversal of the north section happened at 17:00 07 October $(\mathrm{GMT}+8)$ while the northward transport peak of the south section was reached. This is partly due to the fact that a frictional adjustment time is required for the water body to reach a certain speed at which the bottom stress balances the wind shear stress during this period of time. In other words, the northward winds have to overcome the strong southward flow before it leads a northward flow. The previous studies $[1,5]$ demonstrated that the monsoon winds can also lead the currents in the Taiwan Strait for the same reason.

Wu et al. [5] derived a statistical formula between volume transport through the Taiwan Strait and along-strait wind stress obtained by averaging the QSCAT wind stress in the domain $118{ }^{\circ} \mathrm{E}$ to $120{ }^{\circ} \mathrm{E}$ and from $23{ }^{\circ} \mathrm{N}$ to $25^{\circ} \mathrm{N}$. Their results presented that the volume transport through the strait is not only contributed by wind stress but also a surface pressure gradient force. It is indicated in Fig. (9a) that wind stress term resulted in the evident contribution to the southward transport events over the north section at 01:00 LST 07 October, almost in accordance with the southward peak of the water level gradient term at 02:00 07 October (GMT+8). It should be noticed that the peak of the southward transport over the north section begins to decrease with respect to the decrease of southward dynamical forces of wind stress and water level gradient terms, but with the increase of the atmospheric gradient term. The output results in Fig. (10) exhibit that the influences of the dynamical forces on the transport events are significant over the north section (Fig. 10a) than those over the south section (Fig. 10b). It is usually known that the typhoon structure becomes weak due to energy decreasing by bottom friction of land. Accordingly, the southward wind, as Typhoon KROSA moved close to the 

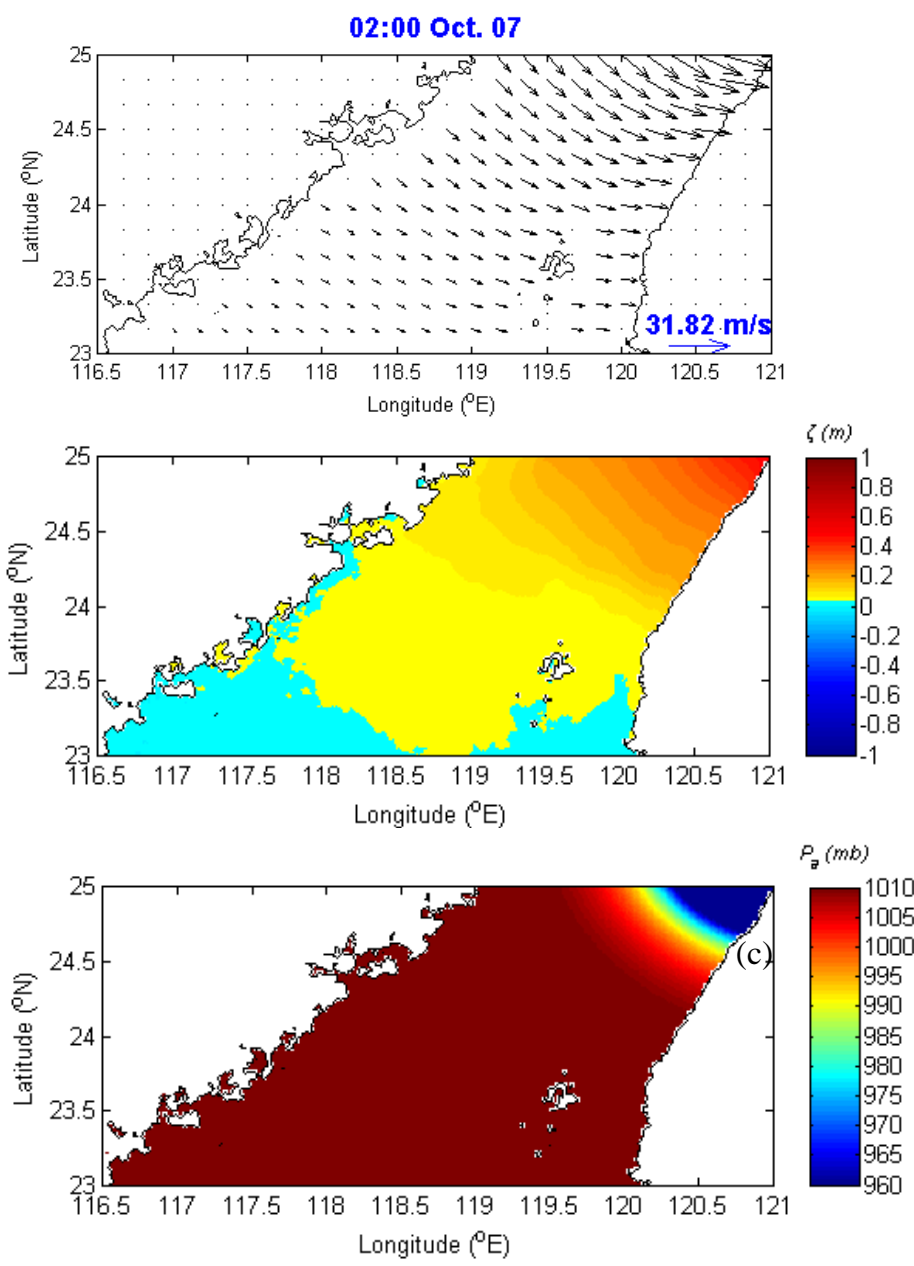

Fig. (10). The modeling results for (a) the distribution of the wind vectors; (b) the water level pattern and (c) the atmospheric pressure field in the Taiwan Strait at 02:00 07 October $(G M T+8)$.

Taiwan Strait, is stronger than the northward wind, as typhoon made landfall on the mainland. Even if the typhoon winds do not become weak after the typhoon center leaves the strait, the northward winds must first overcome the inertial motion of the southward currentts induced by the preceding southward winds before the transport reversal is reached. Therefore, it is hard to induce the northward transport in the Taiwan Strait behind the typhoon center in the Taiwan Strait without the contribution of the atmospheric pressure gradient term to the northward transport.

\subsection{Numerical Experiments}

The influences of grid resolution and dynamical forces on COMCOT-S have been investigated using an additional six numerical experiments shown in Table 5. Fig. (11a) compares time series of the simulated current speeds for THL1 according to the grid resolution and dynamic influences in the latitudinal directions, respectively. Comparisons between the simulated and observed current data according to the grid resolution reveal that the modeling results of Exp. 1 overestimate the current peak of about $0.0732 \mathrm{~m} / \mathrm{s}$. However, the results of Exp. 2 show a smaller underestimation of about $0.0368 \mathrm{~m} / \mathrm{s}$ in comparison with Exp. 1. The modeling results of Exp. 3 present the best performance in reproducing the observed peaks of the current speeds, with a slight un- derestimation of about $0.015 \mathrm{~m} / \mathrm{s}$. The comparisons of the best performance of grid resolution in Fig. (11a) with different dynamical influences show that Exp. 4 present the largest underestimation of about $0.1152 \mathrm{~m} / \mathrm{s}$. In Fig. (11b), it is demonstrated that the finer grid would have the better performance in RMS errors. In addition, it is also found that the largest RMS error is occurred in Exp. 6, which implies the significance of bottom frictional effect in the coastal area.

In order to realize the characteristics of the transport reversal and analyze the influences of the dynamic forces on the volume transport events through the Taiwan Strait, the comparisons between the calculating transport (Exp. 3) and other three numerical experiments (Exp. 4 6) over the north and south sections are illustrated in Fig. (12a, b), respectively. It can be seen from Fig. (12a) that the Coriolis force made a negative contribution to the southward transport events, leading the transport reversal in the north section. It is also remarkable in Fig. (12b) that an evident difference of the southward transport peaks between the simulating transport (Exp. 3) and Exp. 4 was occurred in the south section. As compared with the influence of the Exp. 4, it seems that the Exp. 5 and 6 have less effect on the transport events in the Taiwan Strait. 

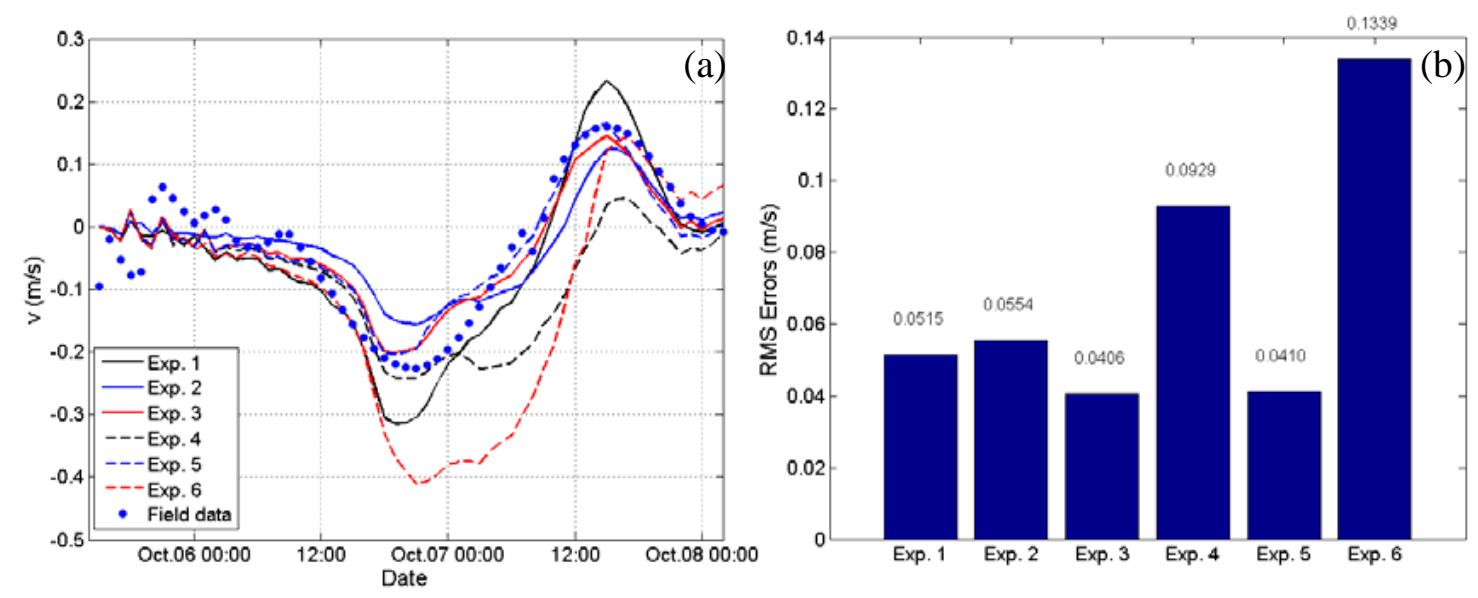

Fig. (11). (a) The comparison of the current speed in the latitudinal direction for THL1 between the field data and the numerical experiments; and (b) RMS errors between numerical experiments and observations during the period of Typhoon KROSA.

Table 5. The Experiments Investigating the Influences of the Grid Resolution and Dynamic Forces on COMCOT-S

\begin{tabular}{|c|c|c|c|}
\hline Case name & Grid Resolution & Type \\
\hline \hline Exp.1 & & $6 \min (\sim 10.8 \mathrm{~km})$ & $*$ \\
\hline Exp. & & $3 \min (\sim 5.4 \mathrm{~km})$ & $*$ \\
\hline Exp. 3 & & $1 \min (\sim 1.8 \mathrm{~km})$ & \\
\hline & & $1 \min (\sim 1.8 \mathrm{~km})$ & without Coriolis force \\
\hline Exp.4 & & $1 \min (\sim 1.8 \mathrm{~km})$ & without nonlinear advective term \\
\hline Exp.5 & & $1 \min (\sim 1.8 \mathrm{~km})$ & without bottom frictional force \\
\hline
\end{tabular}
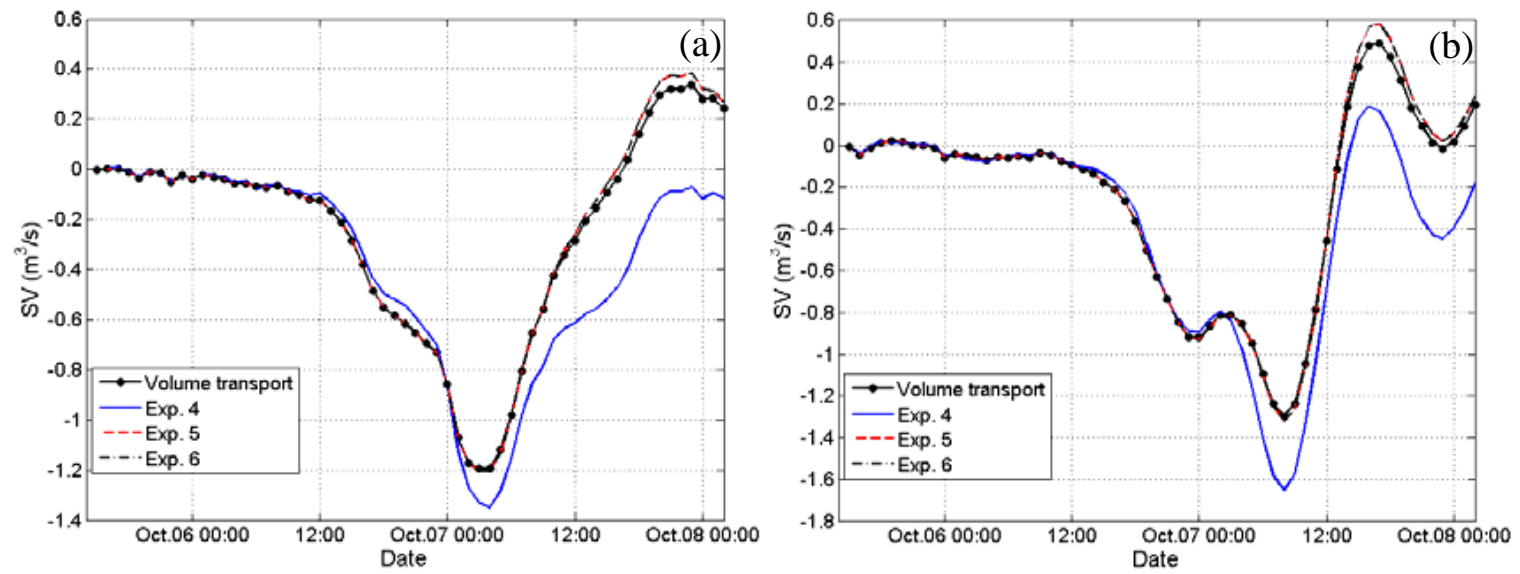

Fig. (12). Time series of volume transport events in the (a) north and (b) south sections. The black solid lines with solid circles denote the simulating results of volume transport, the blue solid lines represent the results of Exp. 4, the red dashed lines are of Exp. 5, and the black dash-dotted lines are of Exp. 6.

The sequent plots for the variation of current vectors without the influence of Coriolis force (Exp. 4) in the Taiwan Strait as compared with those in Fig. (5a-7a) are shown in Fig. (13). The modeling results present that the typhooninduced currents in Fig. (13b) are stronger in the PHC than in the Taiwan Banks, in contrast to results in Fig. (6a). It is clearly shown in Fig. (12c) that the flow pattern in the CYR rotated anti-clockwisely, appearing a U-shaped type as compared with the eddy generation in Fig. (7a). In Fig. (14), it is verified from the transport calculation of the southward and northward peaks in the Taiwan Banks and the PHC that the Coriolis term actually made the negative contribution to the southward transport, especially in the PHC. The southward peak of $0.74 \mathrm{~Sv}$ through the Taiwan Banks is about one and half times the value of $0.48 \mathrm{~Sv}$ through the PHC although the cross-sectional area of the PHC is only one-fourth of that of the Taiwan Banks. However, the northward peak of $0.36 \mathrm{~Sv}$ through the Taiwan Banks is over three times the value of 

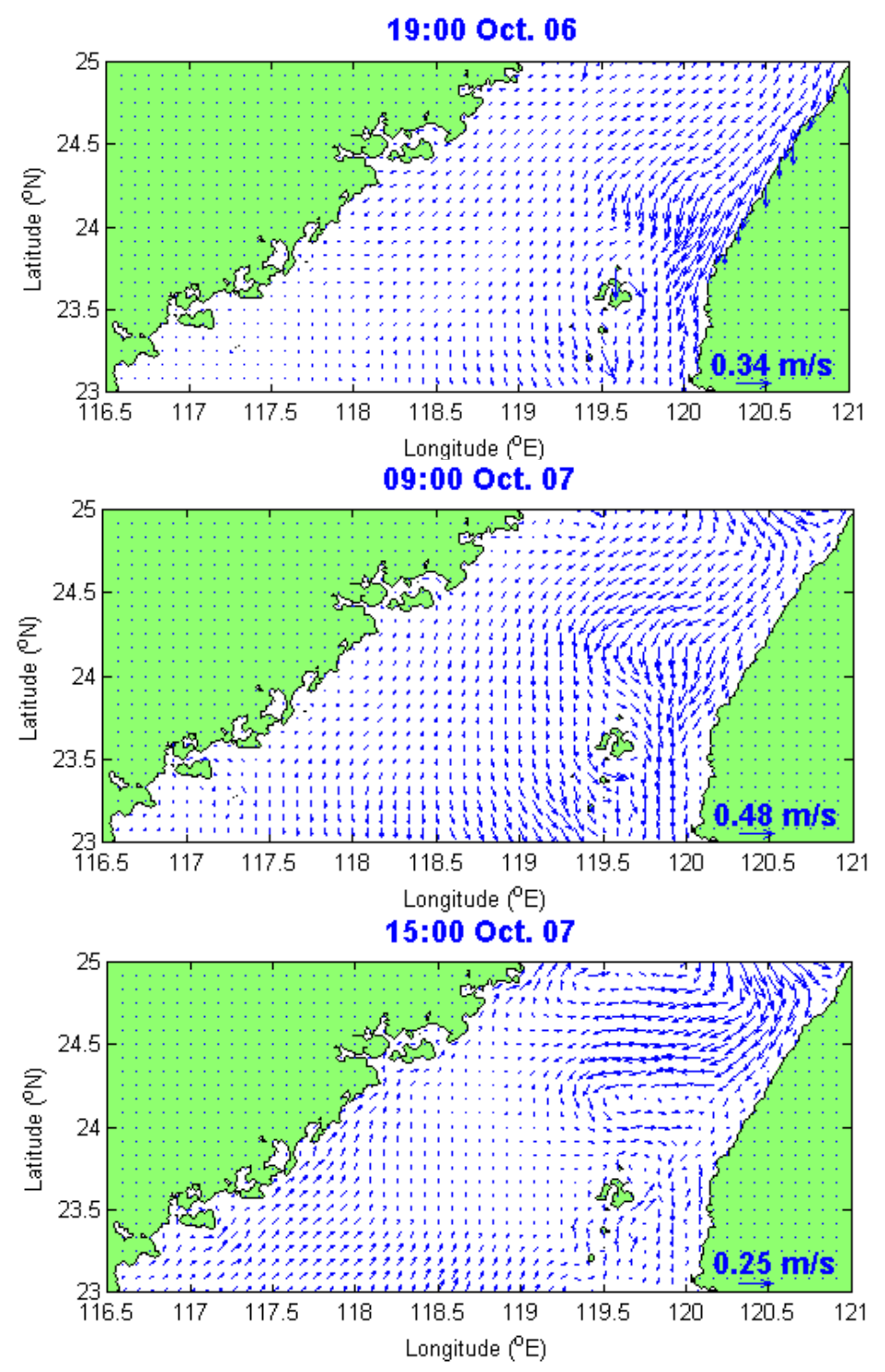

Fig. (13). The variation of typhoon-induced currents for the case of Exp. 4 in the Taiwan Strait at (a) 19:00 06 October; (b) 09:00 07 October and (c) 15:00 07 October (GMT+8), respectively.

$0.11 \mathrm{~Sv}$ through the PHC. Generally, the result reveals the main pathway of typhoon-induced flow during the period of Typhoon KROSA. In addition, transport reversal would not occur in the PHC without the consideration of the Coriolis term. The model results not only lead support to the significance of Coriolis force, but also reveal new features of flow pattern in the Taiwan Strait. The calculation of the Coriolis term is more significant in the PHC than that in the Taiwan Banks. It can be realized that the formation of the anticyclonic eddy would not be reached without the contribution of the Coriolis force during the period of the northward transport in the Taiwan Strait.

\section{CONCLUSIONS}

A comprehensive numerical model, COMCOT-S, has been applied to simulate the storm-induced currents and transport variation in the Taiwan Strait by 2007 Typhoon KROSA. The present research indicates that the modeling winds and currents are in good agreement with the observa- tions at THL1, showing a higher relationship between local winds and currents as well. The concluding remarks are briefly listed as follows:

1. The typhoon-induced currents were found to be highly sensitive to the typhoon winds before the flow reversal at THL1. The results show that the northward currents did not fully response to the cease of the northward winds, representing the influence of other dynamical forces on the flow orientation in the Taiwan Strait.

2. The transport reversal of the north section occurred while the northward transport peak of the south section was reached, partly due to the fact that a frictional adjustment time is required for the water body to reach a certain speed at which the bottom frictional stress balances the wind shear stress during this time lag.

3. According to the transport analysis, the southward transport peak of the north section would begin to decrease 


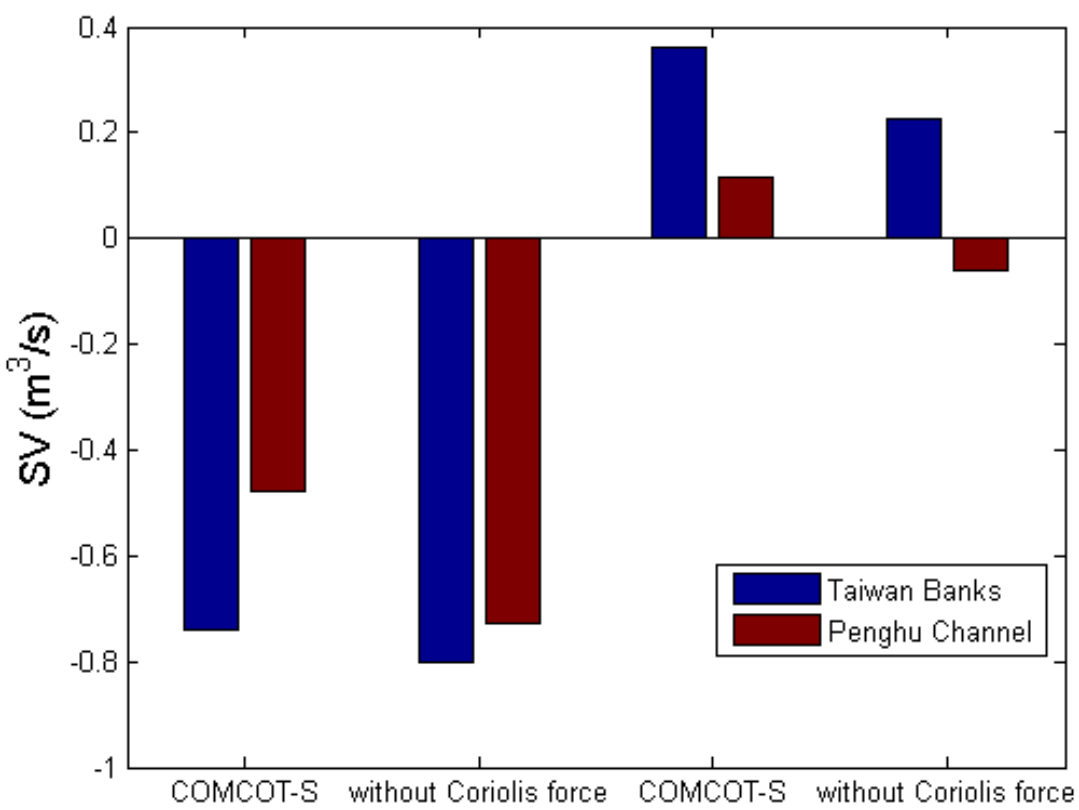

Fig. (14). The volume transport through the Taiwan Banks (blue bars) and the Penghu Channel (red bars) for the cases of simulating results by COMCOT-S as well as the results without the influences of Coriolis force (Exp. 4).

with respect to the decrease of wind stress and water level gradient, but with the increase of the atmospheric pressure gradient. Based on our simulating results, it's demonstrated that the atmospheric pressure gradient would contribute to the transport reversal in the Taiwan Strait predominantly. In addition, it is relevant that the direct contribution of typhooninduced dynamical forces to the transport events is more dominant in the north section than in the south section during the period of Typhoon KROSA.

4. From the results of our numerical experiments, it's verified that the finer grid would have the better performance of flow simulation by RMS error analysis. Moreover, the largest RMS error is occurred in Exp. 6, which implies the significance of bottom frictional effect on the flow calculation in the coastal region.

5. It can be seen from our modeling transport in the Taiwan Strait that the Coriolis force made a negative contribution to the southward transport events, leading the transport reversal in the north section. The dynamic forces of bottom frictional term and nonlinear advective term are found to have less effect on the transport events in the Taiwan Strait.

6 . The results also imply that the calculation of the Coriolis force for the volume transport is more significant in the PHC than that in the Taiwan Banks. The formation of the anticyclonic eddy around the CYR would not be reached without the contribution of the Coriolis force to the northward transport in the PHC.

In summary, the dynamic analysis of transport events in the Taiwan Strait during the period of Typhoon KROSA have been conducted for the occurrence of transport reversal. More case studies of historical typhoons invading Taiwan will be further investigated to understand the transport variation in the Taiwan Strait by considering the astronomical tides and monsoon winds.

\section{ACKNOWLEDEMENT}

This work is sponsored by National Science Counsil NSC 98-2811-E-006-046. The authors are thankful to Tainan Hydraulics Laboratory for providing the valuable field data. Also, special thanks to Dr. Xiao-Ming Wang and Prof. Philip L. -F. Liu for suggestions of this numerical model.

\section{REFERENCES}

[1] C.-R. Wu, S.-Y. Chao, and C. Hsu, "Transient, seasonal and interannual variability of the Taiwan Strait current," J. Oceanogr., vol. 63, pp. 821-833, 2007.

[2] K. Wyrtki, "Physical oceanography of the southeast Asian waters," Scripps Institution of Oceanography, San Diego, Calif 1961.

[3] S. Jan and S. Y. Chao, "Seasonal variation of volume transport in the major inflow region of the Taiwan Strait: the Penghu Channel," Deep-Sea Res. II, vol. 50, pp. 1117-1126, 2003.

[4] Y. H. Wang, S. Jan, and D. P. Wang, "Transports and tidal current estimates in the Taiwan Strait from shipboard ADCP observations (1999- 2001)," Estuarine Coastal Shelf Sci., vol. 57, pp. 193-199, 2003.

[5] C.-R. Wu and Y.-C. Hsin, "Volume transport through the Taiwan Strait: A numerical study," Terr. Atmos. Oceanic Sci., vol. 16, pp. 377-391, 2005.

[6] S., J. Jan, C.-S. Chern Wang and S.-Y. Chao, "Seasonal variation of the circulation in the Taiwan Strait," J. Mar. Syst., 35, doi: 10.1016/S0924-7963(02)00130-6, pp. 249-268, 2002.

[7] W.-Z. Zhang, H.-S. Hong, S.-P. Shang, X.-H. Yan, and F. Chai, "Strong southward transport events due to typhoons in the Taiwan Strait," J. Geophys. Res., vol. 10.114, pp. 1-16, 2009.

[8] D. S. Ko, R. H. Preller, G. A. Jacobs, T. Y. Tang, and S. F. Lin, "Transport reversals at Taiwan Strait during October and November 1999", J. Geophys. Res., 108(C11), 3370, 2003.

[9] W. G. Large and S. Pond, "Open ocean momentum fluxes in moderate to strong winds," J. Phys. Oceanogr., vol. 11, pp. 324-336, 1981

[10] M. D. Powell, P. J. Vivkery, and T. A. Reinhold, "Reduced drag coefficient for high wind speeds in tropical cyclones," Nature, vol. 422, pp. 278-283, 2003.

[11] G. J. Holland, "An analytic model of the wind and pressure profiles in hurricanes," Monthly Weather Rev., vol. 108, pp. 1212-1218, 1980 . 
[12] Phadke, C. Martino, K. F. Cheung, and S. H. Houston, "Modeling of tropical cyclone winds and waves for emergency management," Ocean Eng., vol. 30, pp. 553-578, 2003.

[13] A. Harper and G. J. Holland, "An updated parametric model of the tropical cyclone," in In: Proceedings of the 23rd Conference of Hurricane and Tropical Meteorology Dallas, Texas, 1999, pp. 893896.

[14] L. Bretschneider, "A non-dimensional stationary hurricane wave model," in In: Proceedings of the Offshore Technology Conference. vol. 1, 1972, pp. 51-68.

[15] P. Jelesnianski, "Numerical computations of storm surges without bottom stress," Monthly Weather Rev., vol. 94, pp. 379-394, 1966.
[16] Y. S. Cho, "Numerical simulations of tsunami and runup," Cornell University, 1995.

[17] X. M. Wang and P. L.-F. Liu, "Numerical simulations of the 2004 Indian ocean tsunamis - coastal effects," J. Earthquake Tsunami, vol. 1, pp. 273-297, 2007.

[18] P. L.-F. Liu, S.-B. Woo, and Y.-S. Cho, "Computer Programs for Tsunami Propagation and Inundation," Technical Report, Cornell University 1998.

[19] R. A. Flather, "A tidal model of the north-west European continental shelf," Mem. Soc. R. Sci. Liege, vol. 6, pp. 141-164, 1976.

Received: July 08, 2010

Revised: September 27, 2010

Accepted: September 28, 2010

(C) Lin et al.; Licensee Bentham Open.

This is an open access article licensed under the terms of the Creative Commons Attribution Non-Commercial License (http://creativecommons.org/licenses/by-nc/3.0/) which permits unrestricted, non-commercial use, distribution and reproduction in any medium, provided the work is properly cited. 